16 a 18 de autubro de 2019 - Campinas | Brasil

\title{
Vantagens do precoating em Filtros de Mangas
}

\section{Mateus B. S. Apparecido*, Mônica L. Aguiar, Simone A. Pozza.}

\section{Resumo}

São diversas as modificações e avanços aplicados em políticas ambientais em prol da qualidade do ar ao redor do mundo. Para atingir metas, planos de monitoramento e devido à restrição dos limites na emissão de particulados, promove-se o desenvolvimento de tecnologias e de equipamentos de controle da poluição (ECP) do ar. Um dos desafios é o aumento da eficiência de filtros, que está diretamente relacionada ao aumento da perda de carga $(\Delta \mathrm{P})$, pois comumente utiliza-se meios filtrantes mais fechados e restritivos à passagem do ar. Este parâmetro tem influência direta no consumo de energia elétrica e custos de aquisição e operação dos ECPs. Assim, esse estudo contribui para a otimização de um Filtro de Mangas, prevendo o aumento de sua eficiência na coleta de partículas e à redução do gasto energético do equipamento. Isso foi realizado com a aplicação de um pré-tratamento no meio filtrante, chamado Precoating.

\section{Palavras-chave:}

Filtro de Mangas, Precoating, Qualidade do Ar

\section{Introdução}

Estudos $^{[1]}$ já mostraram os riscos da exposição às partículas finas como o MP10 que atingem as regiões do trato respiratório, enquanto MP2,5 promove danos nas regiões alveolares. Além disso, há elevação nos índices de mortalidade e internações em decorrência dessa poluição atmosférica, como alerta a Organização Mundial da Saúde $(\mathrm{OMS})^{[2]}$.

Algumas partículas, possuem maior potencial negativo à saúde humana devido a sua capacidade de penetração no tecido pulmonar e por sua composição físico-química agressiva e tóxica aos sistemas biológicos. Nas indústrias, a fim de reduzir a emissão de material particulado (MP), um dos equipamentos de controle da poluição (ECP) mais utilizado é o Filtro de Mangas. Tal ECP é capaz de filtrar grandes volumes de ar de forma relativamente econômica. Além, da excelente ${ }^{[3]}$ eficiência na retenção de partículas em extensa faixa granulométrica ${ }^{[4]}$, capturando até mesmo as mais finas (menores do que 2,5 micrômetros). A Fig. 1 mostra um sistema de retenção de MP, utilizando um Filtro de Mangas.

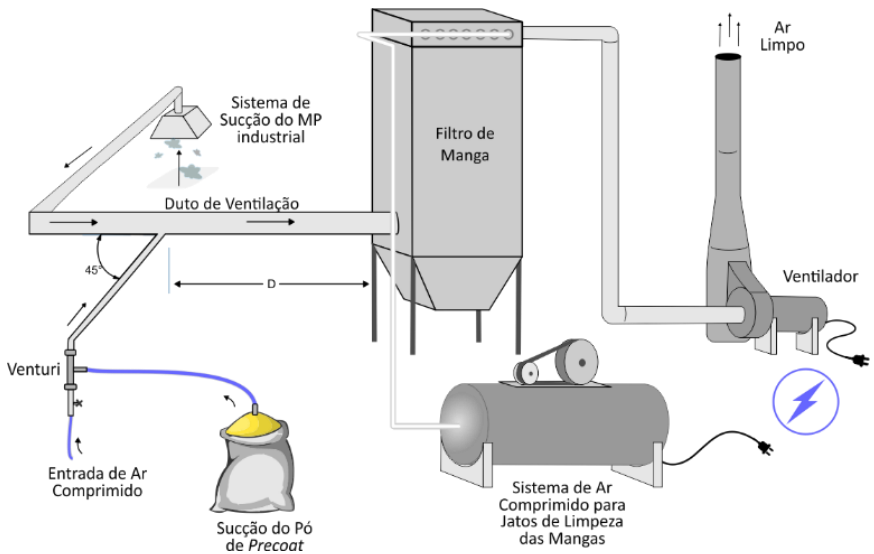

Figura 1. Filtro de Mangas

A manga filtrante é confeccionada por tecido natural ou sintético e, se assemelha a uma manga de camisa, que envolve uma estrutura metálica cilíndrica de estruturação, chamada gaiola. Este conjunto é o responsável pela coleta do MP. O meio filtrante algumas vezes fica exposto a fagulhas, rasgos e entupimento. Então, há necessidade da proteção do tecido da manga. Como alternativa a isso, o precoating pode ser realizado para melhorar eficiência de filtração, principalmente quando a manga está nova.

\section{Resultados e Discussão}

O pó de precoating promove um entupimento controlado dos poros do tecido, e então passa a prevalecer a filtração superficial pela própria torta formada, que favorece a melhora ${ }^{[5]}$ da eficiência de coleta devido a espessura adicional. Há também uma menor perda de carga em decorrência da maior porosidade ${ }^{[6]}$ do novo meio coletor, que é a torta de precoat. Vantagem essa que prolonga[7] a vida útil da mangas filtrantes devido[8] a redução da frequência de limpeza, já que essa torta se desprende mais facilmente. Assim, promove-se economia de energia elétrica tanto do ventilador quanto do compressor, além da redução dos custos operacionais de manutenção.

\section{Conclusões}

É essencial a busca pela redução dos riscos às exposições aos particulados. Por isso, na indústria devese otimizar os ECPs, para reduzir seus impactos na qualidade do ar. Assim, a utilização da técnica de precoating é uma alternativa mais econômica do que a aquisição de mangas com filtrantes de alto desempenho, quando aplicável, ou mesmo para proteção desses tecidos. Desse modo, não requer grandes investimentos e pode ser realizado por mais indústrias, viabilizando a redução da emissão de MP e gastos energéticos.

\section{Agradecimentos}

Ao Grupo de Controle Ambiental do DEQ-UFSCar.

[1] Coelho, C. D.; Tese de Doutorado. Faculdade de Medicina. USP. 2009 [2] World Health Organization (WHO), Air Quality Guidelines - Global Update. 2005. Disponível em: <http://www.euro.who.int/_data/assets/pdf_file/0005/ 78638/E90038 .pdf?ua=1> Acesso em 10 de julho de 2019.

[3] Schiller, S.; Schmid, H. -J.; Powder Technology, 2015, 279, pp. 96 - 105. [4] Mukhopadhyay, A.; Textile Progress, 2009, 41(4), pp. 195-315

[5] Andrade, B.K.S.A.; Dissertação de Mestrado. DEQ-UFSCar. 2019.

[6] Aguiar, M. L.; Coury, J. R.; Ind. Eng. Chem. Res. 1996, 35, pp. 3673-3679.

[7] Carvalho, M. V. A.; Dissertação de Mestrado. DEQ-UFSCar. 2018.

[8] Cirqueira, S. S. R.; Dissertação de Mestrado. DEQ-UFSCar. 2017. 